\title{
Quantitative Estimation of the Impact of Precipitation and Land Surface Change on Hydrological Processes through Statistical Modeling
}

\author{
Muhammad Saifullah, ${ }^{1,2}$ Zhijia Li, ${ }^{1,2}$ Qiaoling Li, ${ }^{1,2}$ \\ Muhammad Zaman, ${ }^{3}$ and Sarfraz Hashim ${ }^{1}$ \\ ${ }^{1}$ College of Hydrology and Water Resources, Hohai University, Nanjing 210098, China \\ ${ }^{2}$ National Cooperative Innovation Center for Water Safety \& Hydro-Science, Hohai University, Nanjing 210098, China \\ ${ }^{3}$ College of Water Conservancy and Hydropower Engineering, Hohai University, Nanjing 210098, China
}

Correspondence should be addressed to Muhammad Saifullah; saif@hhu.edu.cn and Zhijia Li; zjli@hhu.edu.cn

Received 3 January 2016; Revised 13 March 2016; Accepted 14 April 2016

Academic Editor: Hung Soo Kim

Copyright ( 2016 Muhammad Saifullah et al. This is an open access article distributed under the Creative Commons Attribution License, which permits unrestricted use, distribution, and reproduction in any medium, provided the original work is properly cited.

Precipitation variability and land surface changes are the two primary factors that affect basin hydrology, and thus estimation of their impact is of great importance for sustainable development at a catchment scale. In this study, we investigated the long-term changes in precipitation and runoff, from 1961 to 2011, in the Yihe River basin by Mann-Kendall test. A new method of trend pattern was put forward and used to identify the trends of precipitation and runoff, which indicated that the basin had a decreasing trend in annual runoff. The change point occurred in the year 1985 dividing the long-term series into two periods. Precipitation elasticity and linear regression methods were used to quantify the impact of precipitation and land surface change on runoff and provided consistent results of the percentage change in an annual runoff for the postchange period. Use of these methods reveals that the reduction in annual runoff is mainly due to precipitation variability of $56.38-67.68 \%$ and land surface change of $43.62-32.32 \%$, as estimated by precipitation elasticity and linear regression methods, respectively. Due to the rapid growth of urbanization, the land surface change increased from 1990 to 2010 . The result of this study can provide a reference for the management of regional water resources.

\section{Introduction}

The runoff of some rivers in the world especially in the arid and semiarid areas has reduced remarkably due to human activities in the last decades. In addition to precipitation change, increases in land surface changes due to the growth of population such as deforestation, afforestation, and urban constructions have also altered the hydrological process, which leads to a change in the water cycle and affects the runoff [1]. Water resources managers and planners are looking for simple and easy methods to determine the contribution of precipitation and land surface change on runoff, which supports sustainable natural resources development, particularly in the catchment scale. The significant reduction in runoff is a strong indicator of influences of precipitation and land surface changes on the hydrological process of the catchment $[2,3]$. Particularly in China, due to the variation in regional precipitation changes coupled with strong economic and industrial development during the past decades [4], several researchers have paid attention to understand the impacts of precipitation and land surface change on the hydrological process. The runoff reduction in the arid and semiarid areas of China has brought severe difficulties in livelihood and ecology. As a result of the recent intensification of human activities, such as agriculture activities, deforestation, hydraulic projects, and soil and water conservation measures, considerable concentration has been given to assessing the impacts of land surface changes on runoff [5]. It has been an important scientific problem in hydrology to reveal the physical characteristics of the basin 
and trends of runoff change and their influencing factors. Furthermore, the impacts of precipitation and land surface change impacts vary from place to place and need to be identified for local scale.

Much research has been done on the runoff variations of different river basins across the world in the previous few years. According to characteristics of the watersheds, four aspects of studies on runoff changes can be recognized: (1) arid region, for example, quantifying the effects of climate variability and human activities on runoff for Kaidu River basin [6]; (2) semiarid region, many studies discussing the influence of human activities on runoff in this region [7-10]; (3) humid region, for example, the studies on the assessment of climate change and human activities on runoff variation of the Huifa River basin [11]; (4) semihumid region, for example, separating the effect of human activities using different time scale in the Zhang River basin [3, 12].

Several methods have been used to assess the impacts of precipitation and land surface changes on the hydrological processes, but to date, no standard model has been developed. In the past, paired catchment experiment method was used to determine the impact of precipitation and land surface changes on the hydrological process. The experimental methods are time-consuming, expensive, and difficult to locate suitable controls [13-15]. On the other hand, physically based hydrological models, such as soil and water assessment tool, variable infiltration capacity model, the Xinanjiang model, and the HBV model, are always limited due to the time-consuming process of calibration and validation. These models also require extensive and complex dataset and have unpredictable output results, model parameters, and structure [16, 17]. According to methods, these studies could be divided into five categories: (1) time series analysis, for example, the studies on the changing trends and regime shift of streamflow in the Yellow River basin [5]; (2) change point analysis, such as Mann-Kendall rank analysis used to assess the abrupt change in runoff from the Yellow River basin [18]; (3) the rainfall-runoff relationship, for example, the assessment of runoff variation due to human activities in the middle reaches of the Yellow River [19]; (4) statistical analysis, for example, a simple linear regression and multiple linear regression methods used to quantify the human activities on runoff variation in middle reaches of the Yellow River and the Laohahe basin in northern China [20,21]; (5) land use and land surface change impact on runoff variation assessed in West Liaohe River Basin and Yellow River basin $[7,22]$.

However, it is often difficult to get a quantitative estimation of land surface change to runoff variation. The studies for this region found that runoff declined during period 19902000 as compared to period 1980-1990 [23]. Yao et al. [23] found that land surface change leads to reduced runoff in this region. This reduced runoff can cause a severe problem for the environment, the rivers, and estuary ecosystem, and socioeconomic systems. However, the study conducted by Yao et al. [23] focused on peak flow rather than hydrography altered by land surface changes. Further, it also did not quantify the impacts of variations in precipitation and land surface changes in the Yihe River basin. More importantly, the scientific community still expresses a different opinion on how land surface and precipitation variability vary regional water resources in the Yihe River. There is a need to update the knowledge of land surface change and hydroclimatic variables for different rivers, particularly large rivers to assist global as well as regional water resources management. There is a need to study the impact of precipitation and land surface change in the Yihe River basin using simple and easily applicable method. Moreover, some new statistical methods have been developed and used to quantify the impacts of precipitation and land surface changes on the hydrological process of the basin. Before application of these methods, time series data are divided into two periods by an advanced statically method (Pettit's test) and a graphical method, that is, the double mass curve method [21].

The objectives of the present study are (1) to evaluate the new graphical method to determine the trends of low, medium, and high values of precipitation and runoff from the Yihe River basin, which is used for the first time in this region and (2) to develop the linear regression and statistical precipitation elasticity models to assess the impacts of precipitation and land surface changes on hydrological process of the Yihe River basin. This study will deepen our understanding of the runoff response to precipitation and land surface changes in this region, which is crucial for effective planning, management, and sustainable development of water resources in this regions.

\section{Materials and Methods}

2.1. Study Area. One of largest tributaries of the Yellow River is the Yihe River and major upper tributary subbasin of the Yihe River is Dongwan basin, which exists in the semihumid climate zone. The Dongwan watershed is situated in Henan province, China, between longitudes $111^{\circ}$ to $112^{\circ} \mathrm{E}$ and latitudes $33.5^{\circ}$ to $34.5^{\circ} \mathrm{N}$, with a drainage area of $2856 \mathrm{~km}^{2}$ (Figure 1). It drains the mountainous area of Fuinu located in the Qinling Mountain. It is a typical area of the semihumid basin and located in midstream of the Yellow River. The Dongwan basin controls the flood peak and volume of the downstream of Yellow River along with Luhun Reservoir, Sanmenxia Reservoir, Xiaolangdi Reservoir, and Guxian Reservoir.

2.2. Data and Methods. Daily precipitation and streamflow data from 1961 to 2011 at the Yihe River basin were collected from the Yellow River Conservancy Commission. The locations of stations and statistics of the observed records have been presented in Table 1 for precipitation and streamflow time series, respectively. Monthly values are added to get the annual and seasonal precipitation to identify the precipitation trends. The interannual variation in rainfall is significant due to the effect of continental monsoon climate. The study area belongs to a typical semihumid climate, with an average annual precipitation of $766.11 \mathrm{~mm}$ and runoff $219.21 \mathrm{~mm}$ during the past 50 years. The rainfall in the hilly area was more than that in the plain area. Each year, the amount of precipitation for the period from July to September was more than $50 \%$ of the annual precipitation and produces the highest flooding in the period from July to August. 
TABLE 1: Summary of basic statistics of annual precipitation, annual runoff, and land use characteristics of individual stations in the Yihe River basin.

\begin{tabular}{lccccccccccc}
\hline Stations name & Latitude & Longitude & $\begin{array}{c}\text { Mean } \\
(\mathrm{mm} / \text { year })\end{array}$ & $\begin{array}{c}\text { Median } \\
(\mathrm{mm} / \text { year })\end{array}$ & Min. (mm/year) & Max. (mm/year) & Std. & $C_{v}$ & Land use \\
\hline $\begin{array}{l}\text { Precipitation stations } \\
\text { Dongwan }\end{array}$ & 111.98 & 34.05 & 699.29 & 681.00 & 436.00 & 1059.00 & 149.11 & 0.21 & FRST \\
Heyu & 111.90 & 33.85 & 792.67 & 768.30 & 492.20 & 1334.00 & 169.41 & 0.21 & AGL \\
Tantou & 111.73 & 33.98 & 731.38 & 722.75 & 414.10 & 1155.30 & 171.44 & 0.23 & FRST \\
Miaozi & 111.73 & 33.78 & 871.36 & 850.85 & 567.40 & 1401.40 & 176.36 & 0.20 & AGL \\
Luanchuan & 111.60 & 33.78 & 863.81 & 831.20 & 575.60 & 1370.40 & 167.22 & 0.19 & AGL \\
Baishi & 111.55 & 34.02 & 732.51 & 717.45 & 468.70 & 1342.70 & 170.13 & 0.23 & AGL \\
Taowan & 111.47 & 33.83 & 837.61 & 815.50 & 606.90 & 1438.50 & 164.42 & 0.20 & GRL \\
Baitu & 111.43 & 34.05 & 714.50 & 700.65 & 420.40 & 1132.90 & 170.96 & 0.24 & AGL \\
Runoff station & & & & & & & & & & & \\
Dongwan & 111.98 & 34.05 & 219.21 & 172.50 & 83.26 & & 662.62 & 118.93 & 0.54 & FRST \\
\hline
\end{tabular}

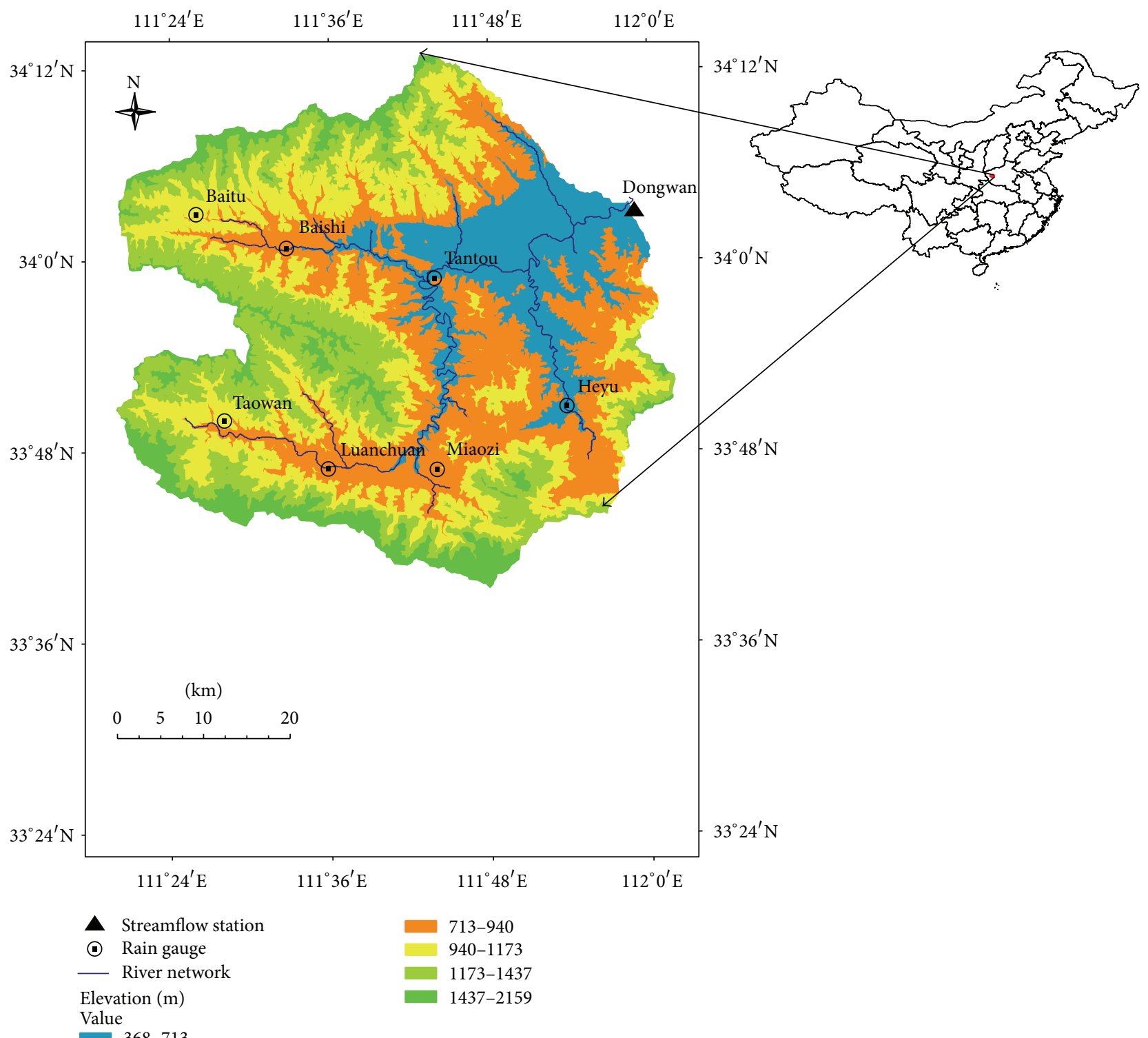

FIGURE 1: Location of precipitation and hydrological stations of Yihe River basin, China. 
Land use and land cover data of 1990, 2000, and 2010 were used in this study at a scale of $1: 100,000$. The dataset which is provided by Data Center for Resources and Environmental Sciences, Chinese Academy of Sciences (RESDC) (http://www.resdc.cn/), was used to test the methods reported in this paper. LULC were classified into 6 classes, forestland, grassland, water body, urban land, agriculture land, and others [24]. In this area, grassland, forestland, and agriculture land are dominant land use type.

2.3. Trend Detection. The nonparametric Mann-Kendall (MK) [25-27] test has been widely used to detect trends in hydrology and climatology $[28,29]$. The MK test static $(S)$ of variables is calculated by

$$
S=\sum_{i=1}^{n-1} \sum_{j=i+1}^{n} \operatorname{sgn}\left(x_{j}-x_{i}\right)
$$

where

$$
\operatorname{sgn}\left(x_{j}-x_{i}\right)= \begin{cases}+1, & x_{j}>x_{i}, \\ 0, & x_{j}=x_{i}, \\ -1, & x_{j}<x_{i},\end{cases}
$$

where $x_{i}$ and $x_{j}$ are the data values at times $i$ and $j$ and $n$ indicates the length of the dataset. While a positive value of $S$ indicates an increasing trend, negative value of $S$ indicates a decreasing trend. The following expression, as an assumption, is used for the series where the data length $n>10$ and data are approximately normally distributed:

$$
V(S)=\frac{n(n-1)(2 n+5)-\sum_{i=1}^{n} t_{i} i(i-1)(2 i+5)}{18}
$$

where $t_{i}$ is the number of data values. After the calculation of the variance of time series data, the standard $Z$ value is calculated according to the following equation:

$$
z= \begin{cases}\frac{S-1}{\sqrt{\operatorname{var}(S)},} & S>0, \\ 0, & S=0, \\ \frac{S-1}{\sqrt{\operatorname{var}(S)}}, & S<0 .\end{cases}
$$

The standard $Z$ value is compared with standard normal distribution table with a two-tailed test at significance level ( $\alpha$ $=10 \%, \alpha=5 \%$, and $\alpha=1 \%)$. If the calculated $Z$ value is greater than $|Z|>\left|Z_{1-\alpha / 2}\right|$, the null hypothesis $\left(H_{o}\right)$ is rejected. Therefore, the trend is statistically significant. Otherwise, the null hypothesis $\left(H_{o}\right)$ is accepted. Therefore, the trend is not statistically significant. In this study, the $95 \%$ confidence level was used for the MK test.

2.4. Innovative Trend Detection Test. Şen [30] divided the time series data into two equal parts and then time series drawn on Cartesian coordinates system which was independent of the trend, preassigned significance level, magnitude of

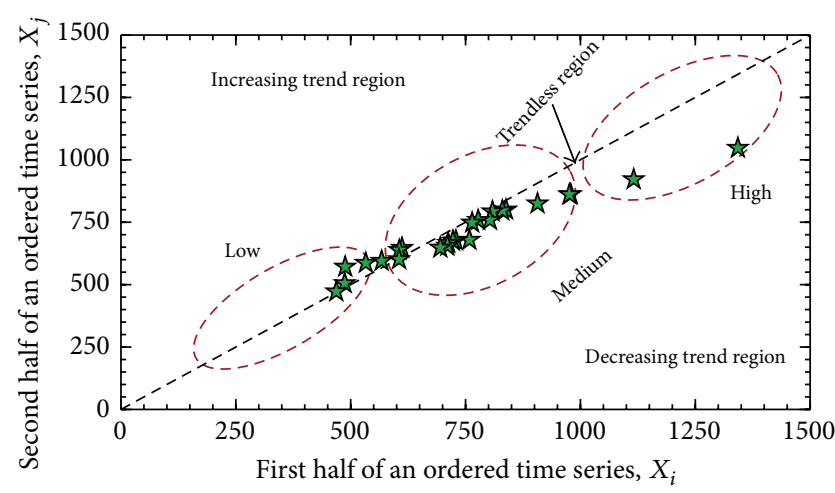

FiguRE 2: Illustration of decreasing, increasing, and trendless region.

the trend, sample size, and amount of variation within time series. The observed hydrological time series is divided into two equal parts from the first date to end date. The division of hydrological time series is based on the change point, which is taken as prechange and postchange time series. Both subseries are separately arranged in ascending order. The first subseries $\left(X_{i}\right)$ is then assigned to $x$-axis, and the other subseries $\left(X_{j}\right)$ is assigned to $y$-axis (Figure 2) based on Cartesian coordinate system. If hydrological time series are plotted on the $1: 1\left(45^{\circ}\right)$ straight line, it can be said that there is a trendless time series. If data values are in below triangular area of a straight line $\left(45^{\circ}\right)$, it can be said that there is a decreasing trend in time series. If data values are in the upper triangular area of a straight line $\left(45^{\circ}\right)$, it can be said that there is an increasing trend in time series [31, 32]. The scatter points above or below the $1: 1$ line indicate increasing or decreasing monotonic trends.

2.5. Change Point Test. Pettit's test [33] is a nonparametric method to identify the occurrence of a change point. It has been commonly used to detect changes in time series data. It is rank based and distribution-free test for detecting an abrupt change in the mean of a time series when the exact time of the change is unknown. The Pettit test can be calculated from the following equation [34]:

$$
U_{t, n}=\sum_{j=1}^{t} \sum_{i=1}^{n} \operatorname{sgn}\left(x_{j}-x_{i}\right), \quad(t=1, \ldots, n),
$$

where the maximum $U_{t, n}$ corresponds to the change point year. We will use Pettit's test to determine the change point of the runoff series as a reconfirmation of the abrupt point identified by a double mass curve.

2.6. Framework for Quantifying the Impact of Climate Change and Human Activities on Runoff. A change in observed mean annual runoff $\left(\Delta Q_{\text {total }}\right)$ may result from precipitation variability $\left(\Delta Q_{p}\right)$ or land surface change $\left(\Delta Q_{L}\right)[20]$ :

$$
\Delta Q_{\text {total }}=\Delta Q_{p}+\Delta Q_{L}
$$

To quantify the impact of precipitation and land surface, we analyzed the variations in a runoff in the prechange period 
and postchange period. Thus, a change in average annual runoff between reference and change period is calculated as

$$
\Delta Q=Q_{2}-Q_{1}
$$

where $\Delta Q$ represents the change in the runoff and $Q_{1}$ and $Q_{2}$ are average annual runoff during the prechange period and postchange period, respectively.

2.7. A Simple Linear Regression. A simple linear regression between annual runoff $\left(Q_{\text {ref }}\right)$ and averaged annual precipitation $\left(P_{\text {ref }}\right)$ in the base period can be expressed as

$$
\mathrm{Q}_{\mathrm{ref}}=a P_{\mathrm{ref}}+b
$$

where $a$ and $b$ are two parameters of the model. Based on (10), the runoff of catchment is calculated as

$$
\begin{aligned}
\Delta Q_{L} & =Q_{\text {fit }}-Q_{\text {change }}, \quad \text { where } Q_{\text {fit }}=a P_{\text {change }}+b, \\
Q_{p} & =Q_{\text {change }}-Q_{\text {ref }},
\end{aligned}
$$

where $Q_{L}$ is the change in mean runoff due to land surface impact, $Q_{\text {fit }}$ calculated runoff during the change period, $P_{\text {change }}$ is rainfall during the change period, and parameters $a$ and $b$ are similar to (8).

2.8. Precipitation Elasticity Method. The precipitation elasticity method was widely used to assess the impact of precipitation and land surface change $[8,10]$. The precipitation elasticity of runoff can be determined by the proportional change in runoff divided by the proportional change in precipitation. The precipitation elasticity of runoff is calculated as follows:

$$
\varepsilon_{p}=\frac{d Q / Q}{d P / P},
$$

where $P$ and $Q$ are precipitation and runoff, respectively. Sankarasubramanian et al. [35] presented a nonparametric approach. The precipitation elasticity of runoff can be expressed as

$$
\frac{\Delta Q_{i}}{\bar{Q}}=\varepsilon_{p} \frac{\Delta P_{i}}{\bar{P}},
$$

where $\Delta Q_{i}$ and $\Delta P_{i}$ are changes of annual runoff and precipitation, respectively. The value of $\varepsilon_{p}$ was estimated using observed precipitation and runoff before the change point. The change in the runoff after change point could be estimated from the precipitation data during the change period using (12). The research framework is shown in Figure 3.

\section{Results}

3.1. Preliminary Data Analysis. The homogeneity of the precipitation time series was assessed by applying standard normal homogeneity test (SNHT) $[36,37]$ and Buishand's range (BR) test [38] at 5\% significant level for each station [28]. All the precipitation series were found to be homogenous. Table 2 presents the results of homogeneity tests for
TABLE 2: Results of homogeneity test for annual precipitation time series at study stations.

\begin{tabular}{lccc}
\hline \multirow{2}{*}{ Station } & SNHT & \multicolumn{2}{c}{ Buishand's range (BR) test } \\
& $T_{o}$ & $Q / \sqrt{ } n$ & $R / \sqrt{ } n$ \\
\hline Dongwan & 5.76 & 0.57 & 0.98 \\
Heyu & 4.02 & 0.81 & 1.32 \\
Tantou & 6.57 & 0.99 & 1.54 \\
Miaozi & 7.05 & 0.82 & 1.42 \\
Luanchuan & 7.04 & 0.82 & 1.05 \\
Baishi & 5.28 & 0.72 & 1.05 \\
Taowan & 2.71 & 0.71 & 1.26 \\
Baitu & 5.52 & 0.60 & 1.13 \\
\hline
\end{tabular}

For homogenous series, $T_{o} \leq 9.17, \mathrm{Q} / \sqrt{ } n<1.27$, and $R / \sqrt{ } n<1.55$.

all precipitation stations. Figure 4 shows long-term variations in annual precipitation $(P)$ and runoff $(Q)$ of the Yihe River basin from 1961 to 2011. The basin exhibited a significant variation in the runoff, whereas the variations in precipitation appeared to be stationary.

3.2. Innovative Trend Pattern of Precipitation and Runoff. In this study, for the stations when the serial correlation was found, trend-free prewhitening approach had been applied. As a summary, statistically significant trends at 95\% were not found in all stations according to the MK trend test. Then trends' pattern of precipitation with Şen's innovative method was used to determine the historical trends of precipitation and illustrated in Figures 5-12. These figures show variations of precipitation in eight stations, and it can be seen as increasing, decreasing, or trendless time series. At Baitu station, the low values of annual precipitation observed a decreasing trend. It is seen that the annual precipitation of Heyu and Luanchuan has no trends for medium values. However, Miaozi, Baishi, Taowan, and Baitu have a decreasing trend for medium values. All stations except Dongwan and Tantou have a downward trend for high values of annual precipitation. In the Baitu station, the low and medium values of spring season have a downward trend; there is no trend for low and medium values for remaining stations. The Tantu, Miaozi, and Baishi stations have no trend for low and medium values for the summer season. However, it is seen that while Taowan station has a decreasing trend for high values, all other stations have an increasing trend for high values of summer precipitation. The Tantou station has an increasing trend for high values and no trend for medium values; the other stations have decreasing trends for low, medium, and high values for the autumn season. All other low, medium, and high values of runoff have a decreasing trend for seasonal and annual time scale (Figure 13). As a summary of trends tests, runoff from the basin shows an obvious declining trend; the variation in precipitation and runoff shows inconsistency. Overall, downward trends have been identified in seasonal and annual, precipitation, and runoff series, indicating that the decrease in runoff may be 


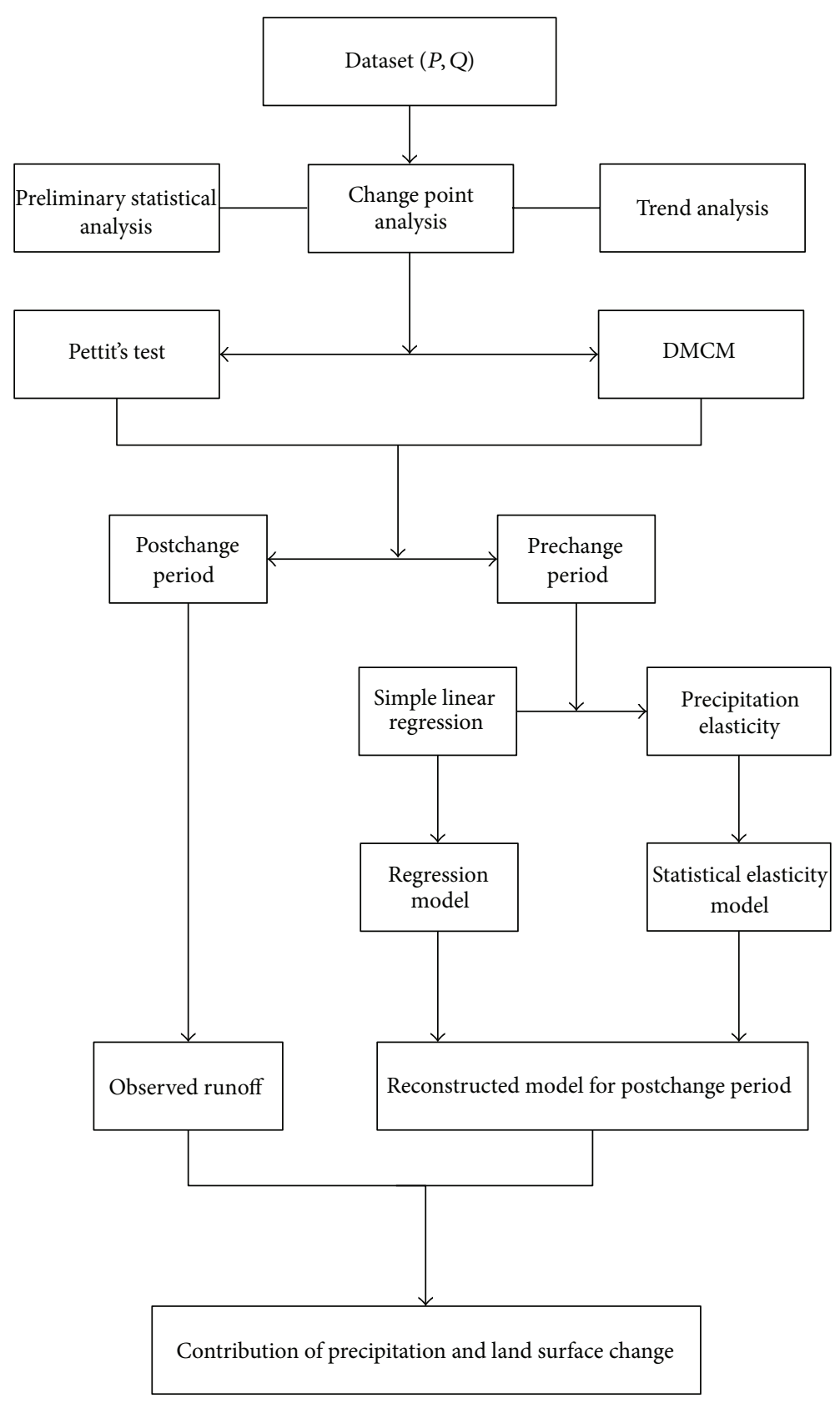

FIGURE 3: Flowchart of methodology.

attributed to trends in precipitation. However, runoff in the study area has reduced more as compared to precipitation. This fact may signify that the linear relationship between precipitation and runoff has altered during the past decades.

3.3. Change Point Analysis. The annual precipitation-runoff double cumulative curve is normally approximate to a straight line if the basin characteristics are stable; thus, a change in the slope of the curve may indicate that the internal relations between precipitation and runoff have altered. The change point in 1985 has only been identified in runoff series. Figure 16 presents the double cumulative curve in a nearly straight line but with different gradient before and after 1985, which may indicate that the process of the runoff production has changed.

To better understand the characteristics of the changes in runoff, the difference between the annual runoff during the prechange period and the annual runoff during postchange period was analyzed using different statistical tests. The significant difference between the means of prechange and postchange periods of slopes of two straight lines can be found at 95\% confidence level using $z$-test. Concurrently, using $F$-test and $t$-test, there are statistically significant differences between the variances of slopes of two lines at $95 \%$ confidence level. The results of two straight lines are consistent with double mass curve lines, which indicate 


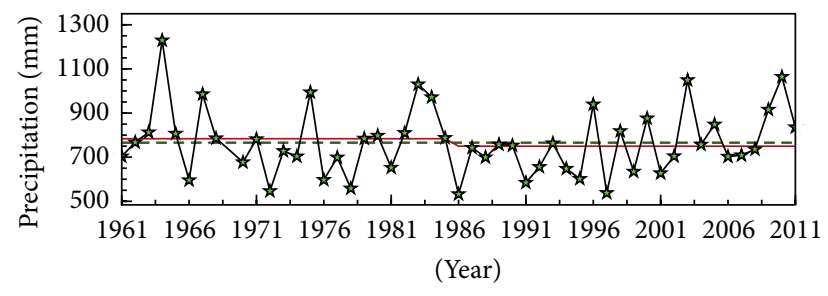

- Average of pre- and postchange

- - - Annual average

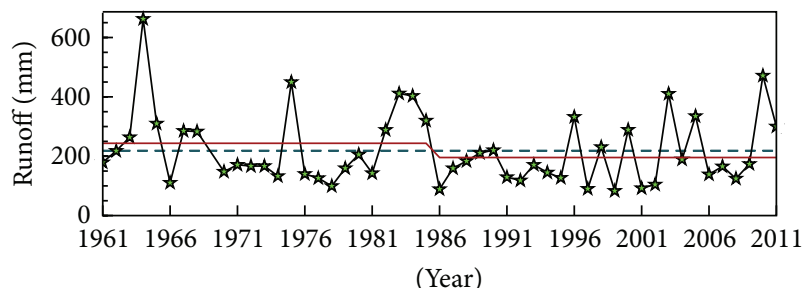

- Average of pre- and postchange

- - - Annual average

FIGURE 4: Time series of annual precipitation $(P)$ and runoff $(Q)$ in the Yihe River basin.

more variation in runoff during the postchange period. Runoff coefficient (slope of lines) of the prechange period is higher $(10 \%)$ than a postchange period. The maximum value of runoff coefficient is 0.34 for the period of 19811985. After 1985, runoff coefficient abruptly decreases half of 1981-1985, which is evidence of the change point. The variations of runoff coefficient during the prechange period to postchange periods are $55 \%$ to $45 \%$. The runoff coefficient of the prechange period is slightly higher than the postchange period. Recently precipitation increases and runoff coefficient is lower than the prechange period.

Hence, combining the results of the change point test and double cumulative curve, the year 1985 could be the change point representing the impact of precipitation and land surface change on runoff. In this study, the double mass curve is used to identify the change point of the runoff series as a confirmation of the change point. However, the reductions were present in average monthly runoff during the postchange period (1986-2011). The greatest decline in runoff is identified in flood seasons (July, August, and September) (Figure 17). The slightly increasing precipitation and consistent largely decreased runoff happen in July (Figures 14 and 15). The reduction in runoff during $1986-2011$ might be due to land surface change. Similar findings were also identified in some previous studies $[21,39]$. Figure 16 shows a correlation comparison of precipitation and runoff for the two periods. The correlation between precipitation and runoff for the prechange period $(R=0.84)$ is stronger than that for land surface change period $(R=0.78)$. This result again indicates that runoff should be affected by the land surface change in this region after 1985 (Table 3). Several researchers used the double mass curve method to verify the change point and found similar results $[19,34]$.
TABLE 3: Summary of annual runoff, precipitation, and runoff coefficient change point.

\begin{tabular}{lcc}
\hline Period & $\begin{array}{c}\text { Prechange } \\
\text { period } \\
(1961-1985)\end{array}$ & $\begin{array}{c}\text { Postchange } \\
\text { period } \\
(1986-2011)\end{array}$ \\
\hline Runoff & & \\
Mean (mm) & 239.66 & 187.44 \\
Standard deviation & 130.25 & 109.24 \\
Precipitation & & \\
Mean (mm) & 781.61 & 749.87 \\
Standard deviation & 159.92 & 139.66 \\
Runoff coefficient (slope) & & \\
Mean & 0.29 & 0.25 \\
Standard deviation & 0.097 & 0.087 \\
\hline
\end{tabular}

TABLE 4: Quantifying the effects of climate variability and human activities on runoff.

\begin{tabular}{lcc}
\hline & Precipitation elasticity & Simple linear regression \\
\hline$Q_{p}$ & 25.79 & 45.74 \\
$Q_{L}$ & 19.95 & 21.84 \\
$Q_{p}(\%)$ & 56.38 & 67.68 \\
$Q_{L}(\%)$ & 43.62 & 32.32 \\
\hline
\end{tabular}

\subsection{Impact of Precipitation and Land Surface Change on} Runoff. The precipitation elasticity of runoff was estimated using (11)-(12) to assess the impact of precipitation change on runoff. The value of $\varepsilon_{p}$ is 2.61 . The results indicate that a $10 \%$ decrease in precipitation would result in $26.1 \%$ decrease in runoff. According to the equation, with the calculated $\varepsilon_{p}$, it can be calculated that the $31.74 \mathrm{~mm}$ decrease of precipitation in 1985-2011 may lessen the runoff by $45.74 \mathrm{~mm}$. Therefore, a $25.79 \mathrm{~mm}$ decrease in annual precipitation in the study area contributes $56.38 \%$ of the total drop in the runoff, while land surface change is responsible for $43.62 \%$ of runoff decrease (Table 4). For the simple linear regression method, the difference of simulated runoff before and after the change point is assessed for the impact of precipitation change. Annual runoff in the study area had reduced from $242.46 \mathrm{~mm}$ in $1961-1985$ to $196.72 \mathrm{~mm}$ in $1986-2011$. The $45.74 \mathrm{~mm}$ of runoff indicates that precipitation change could have accounted for $67.68 \%$ of the runoff reduction. Therefore, land surface change may have resulted in $21.84 \mathrm{~mm}$ decrease in annual runoff, estimating $32.32 \%$ of the runoff reduction. After 1990, land surface change was pointed out in Dongwan basin. The main land cover types of the study area include agriculture, forest, urban, water body, grassland, and other forms (saline, wetland, and barren). The agriculture land, grassland, and forest land are predominant land use types in this study area. From 1990 to 2010, there have been occurring land changes in the basin, such as an increase in urban land, water body, and other types (barren, saline, and wetland) of land and decrease in agriculture land. The area of agriculture decreased from $45.9 \%$ to $44.2 \%$, while other uses of land increased from $0.07 \%$ to $0.17 \%$. From 1990 to 2000 , urban 


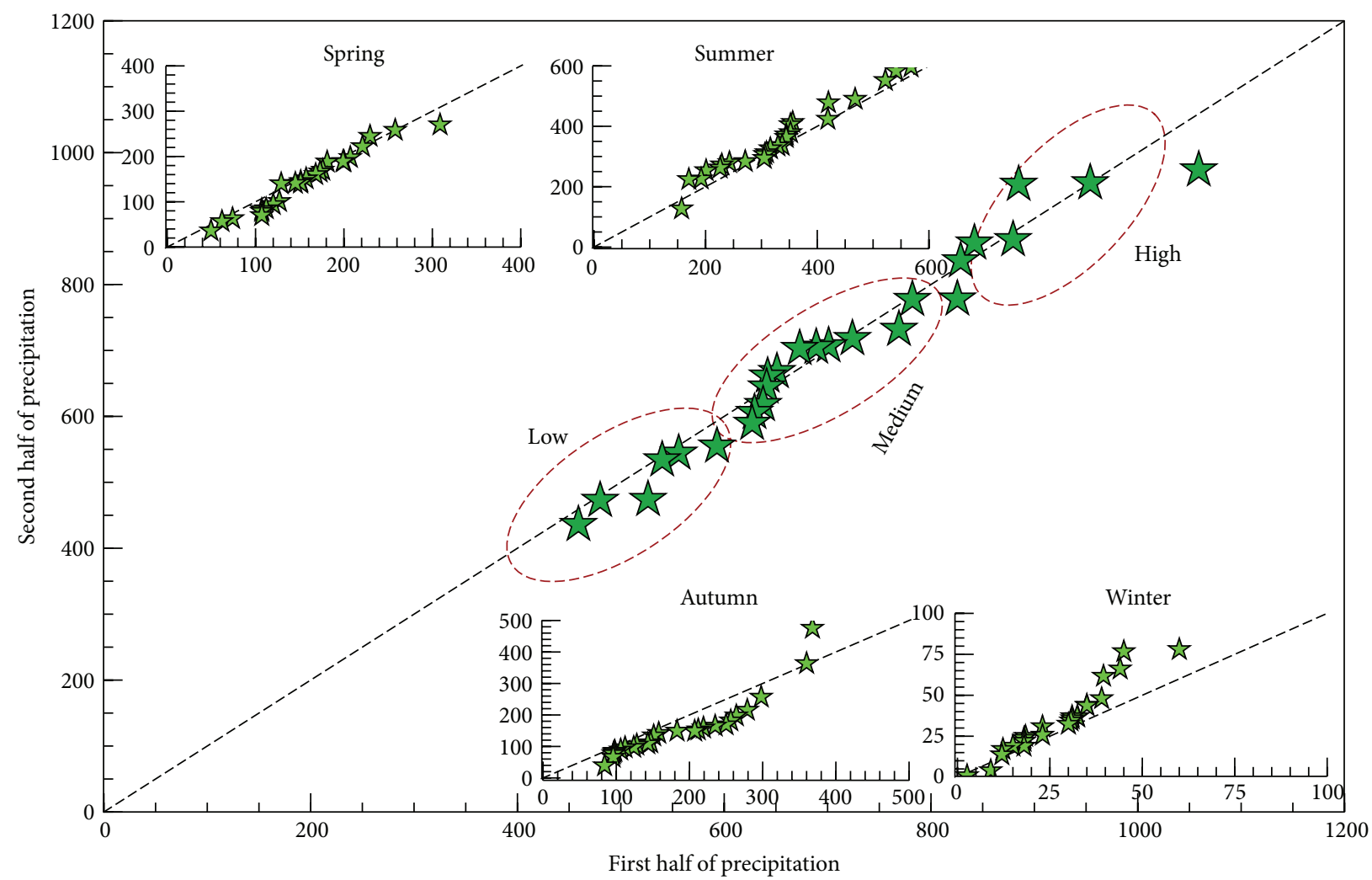

FIGURE 5: The precipitation pattern for Dongwan station as a result of innovative trend test.

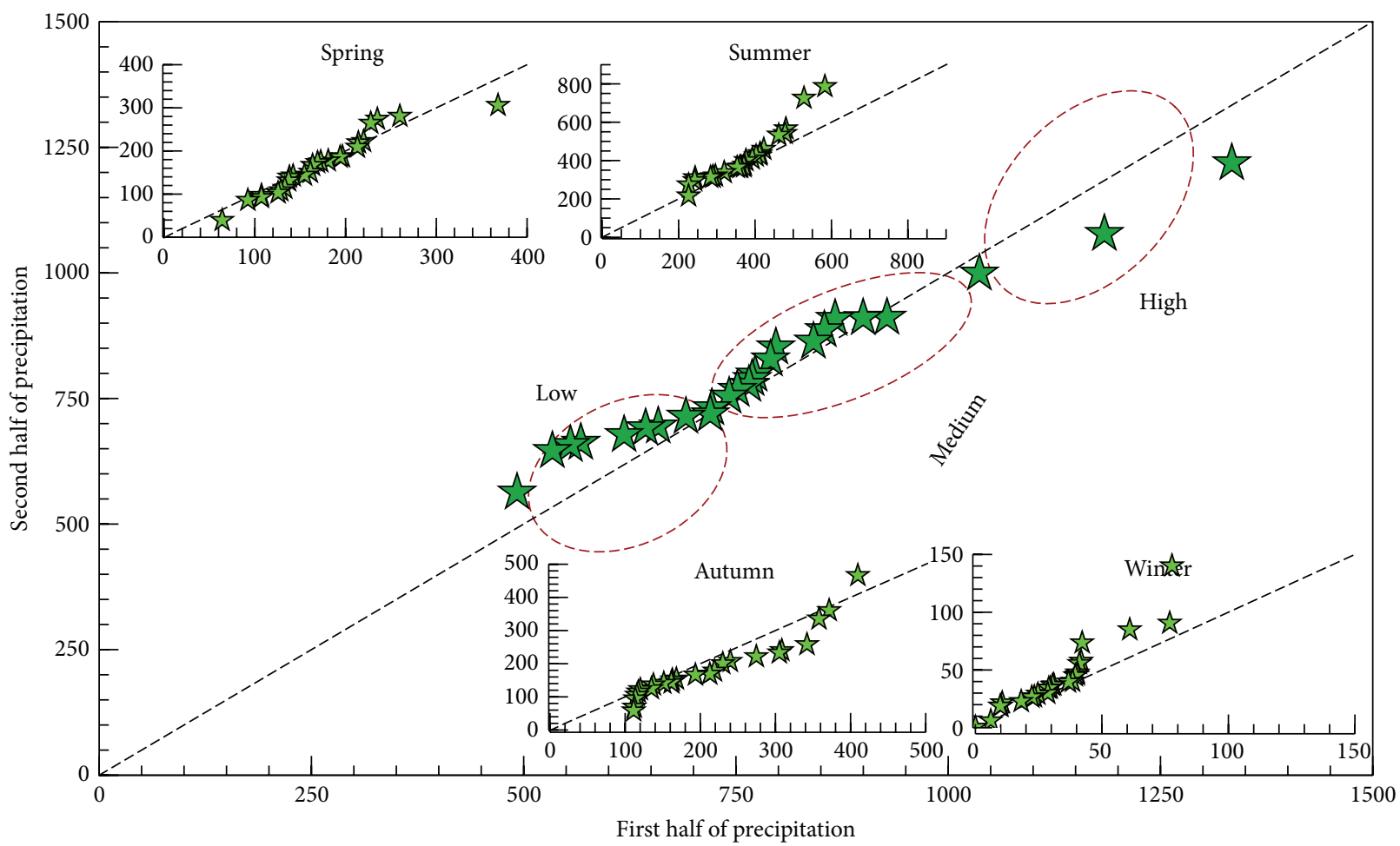

FIGURE 6: The precipitation pattern for Heyu station as a result of innovative trend test. 


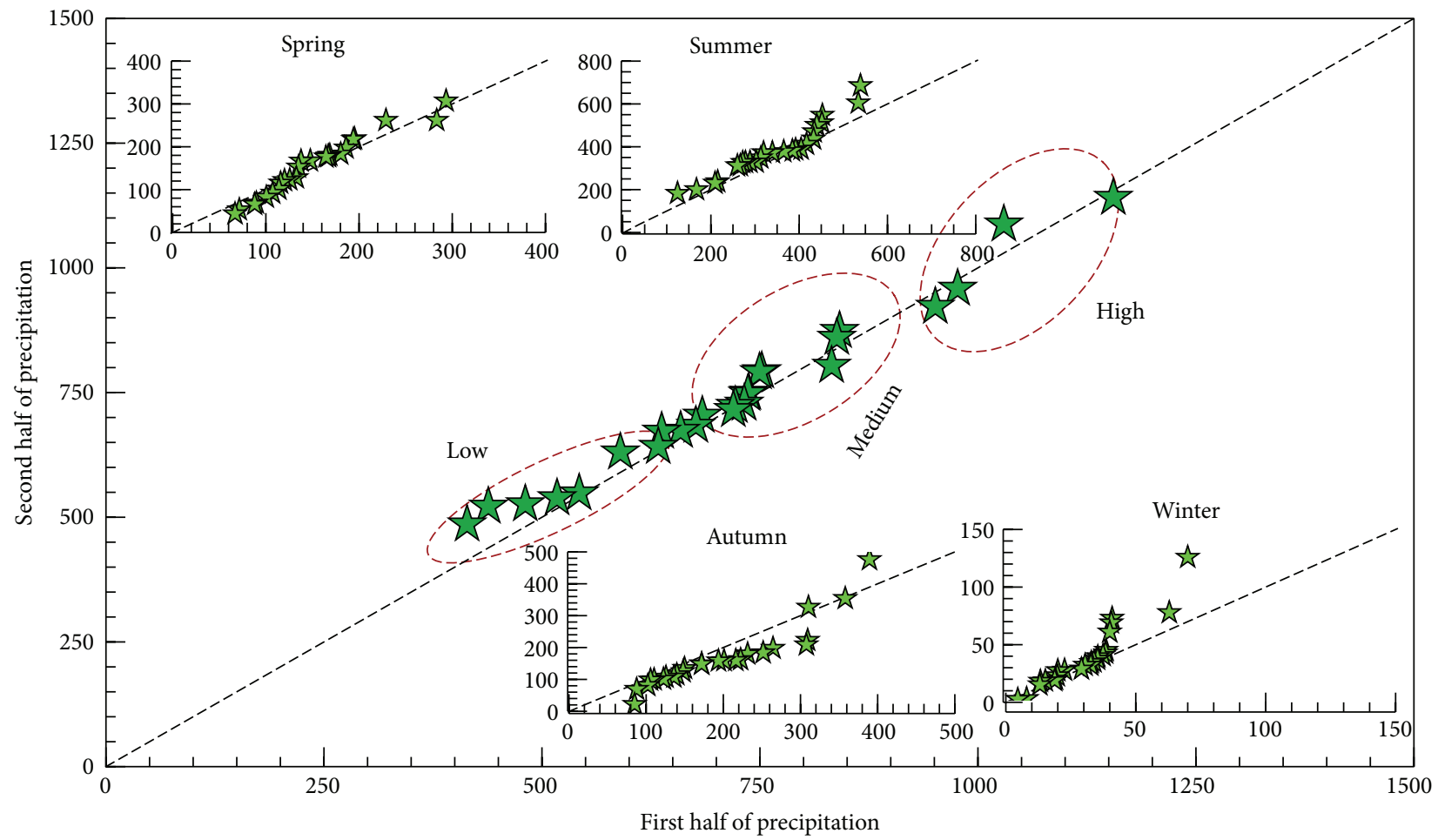

FIgURE 7: The precipitation pattern for Tantou station as a result of innovative trend test.

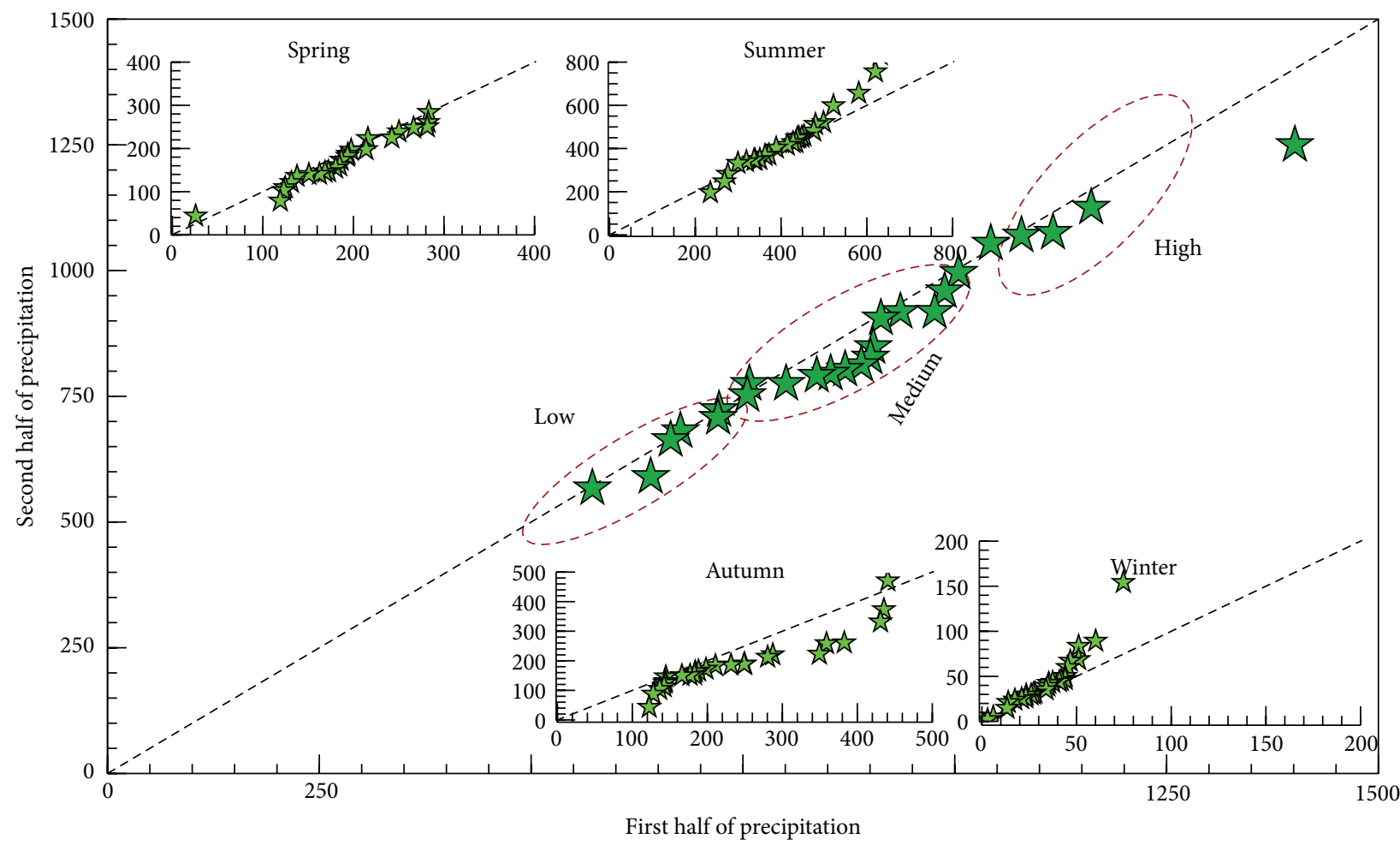

FIGURE 8: The precipitation pattern for Miaozi station as a result of innovative trend test. 


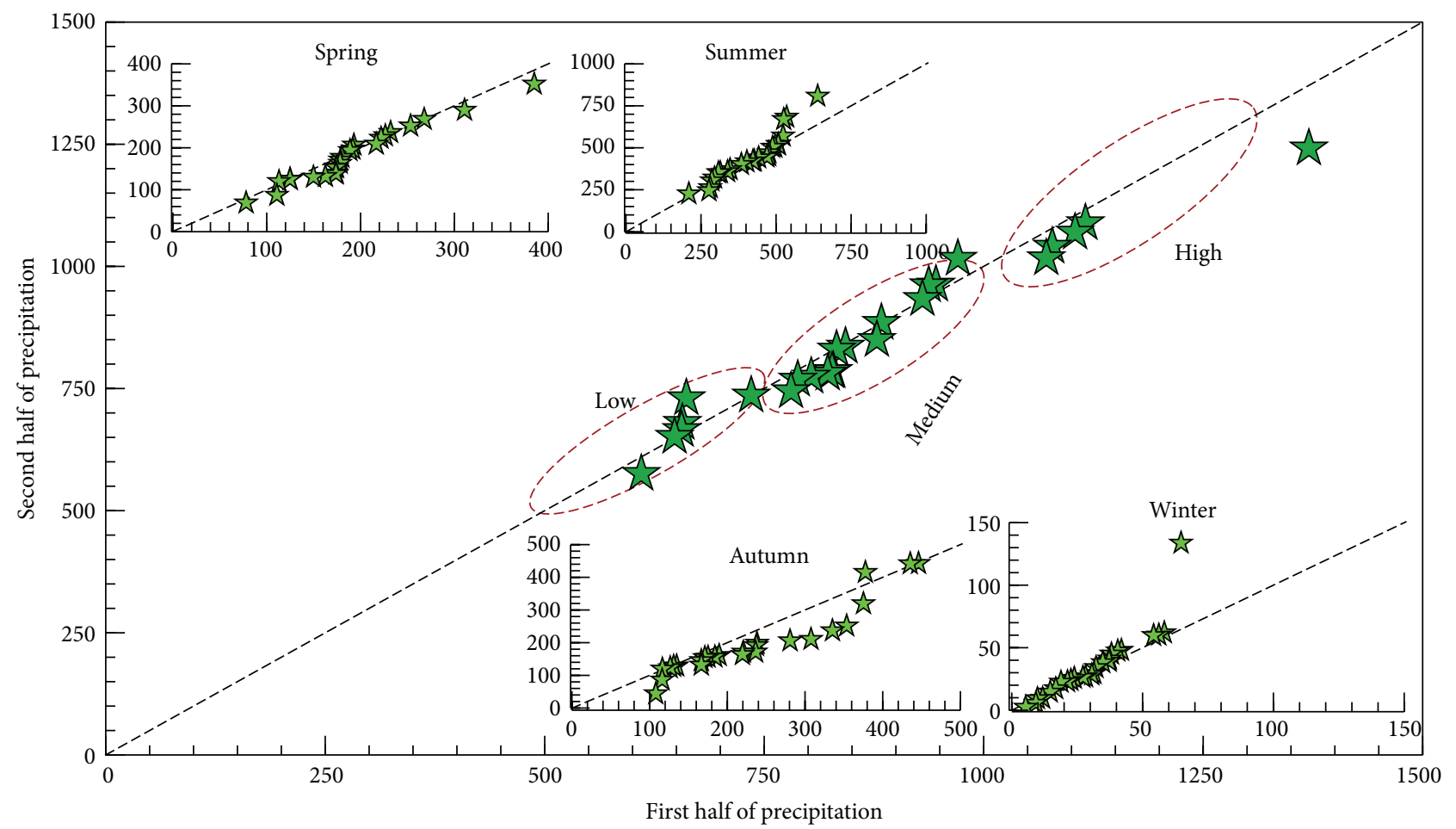

FIGURE 9: The precipitation pattern for Luanchuan station as a result of innovative trend test.

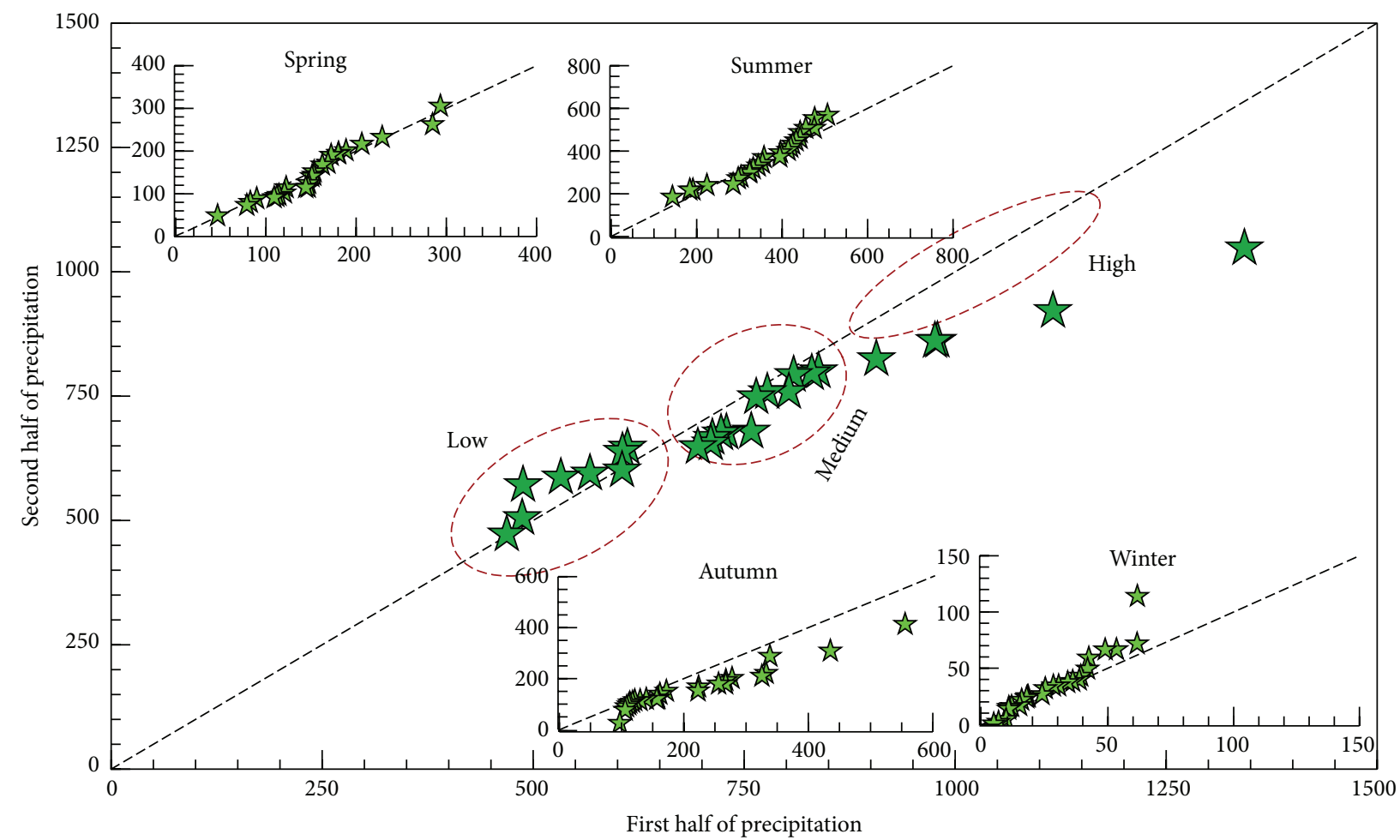

FIGURE 10: The precipitation pattern for Baishi station as a result of innovative trend test. 


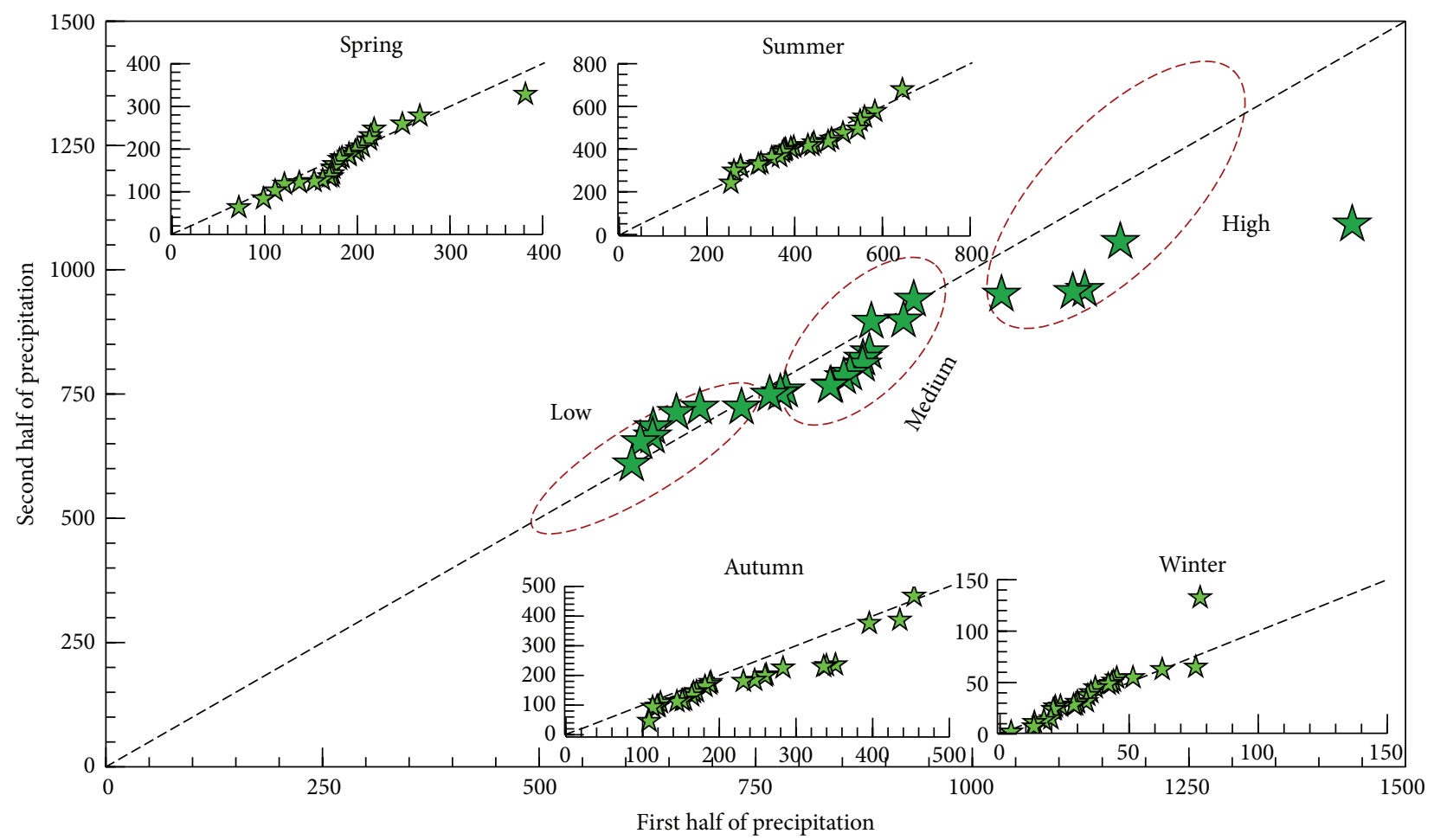

FIGURE 11: The precipitation pattern for Taowan station as a result of innovative trend test.

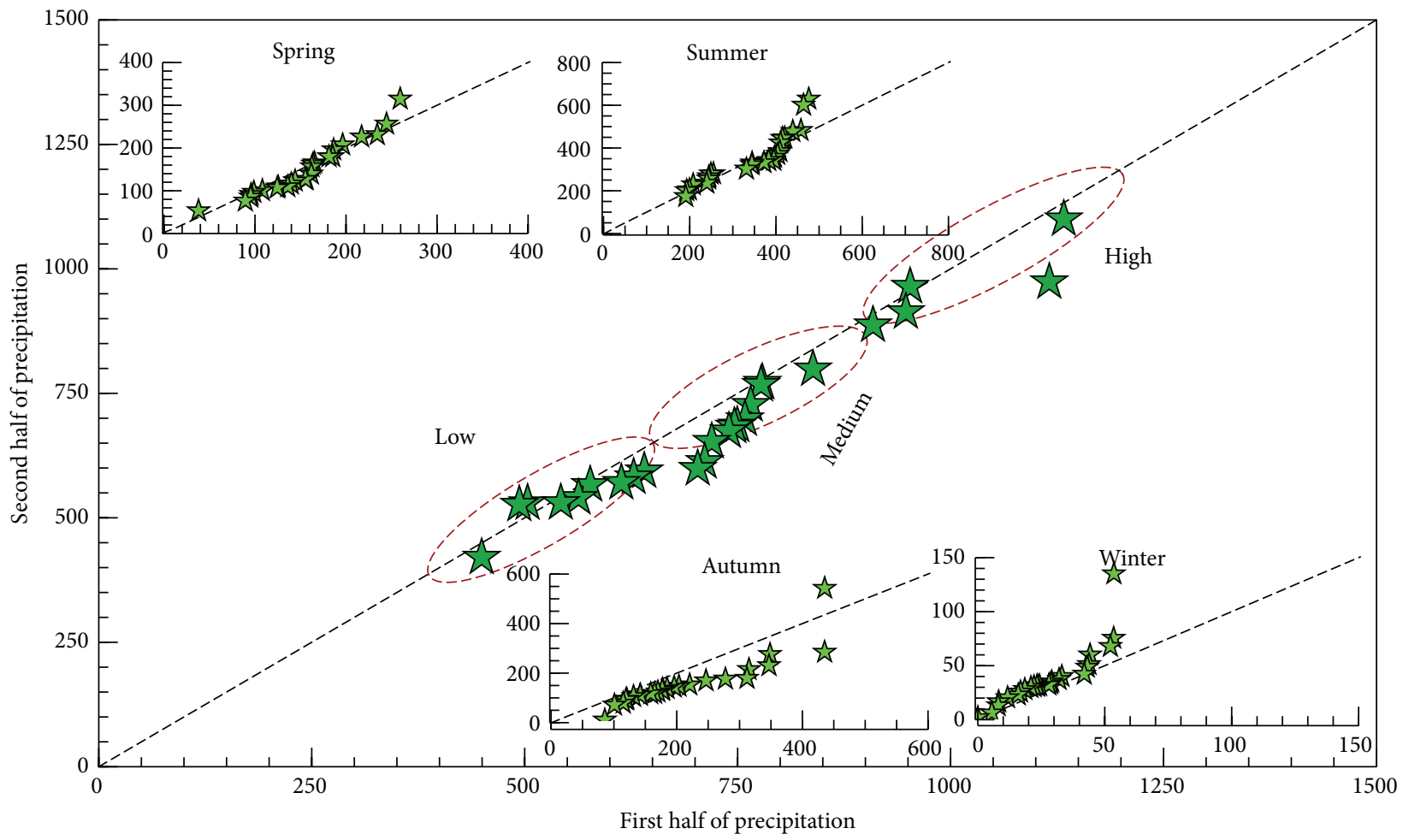

FIGURE 12: The precipitation pattern for Baitu station as a result of innovative trend test. 


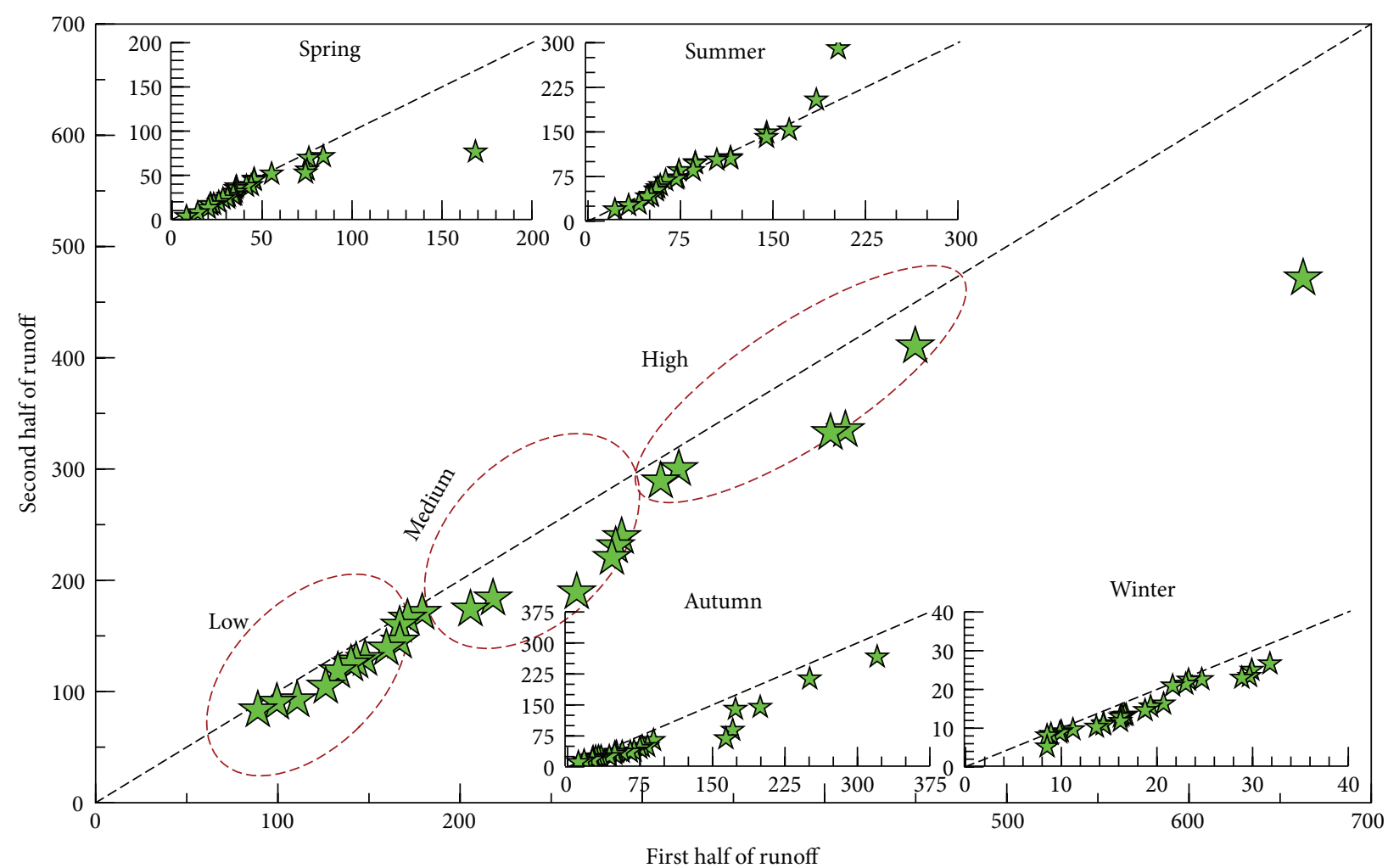

FIGURE 13: The runoff pattern for Dongwan station as a result of innovative trend test.

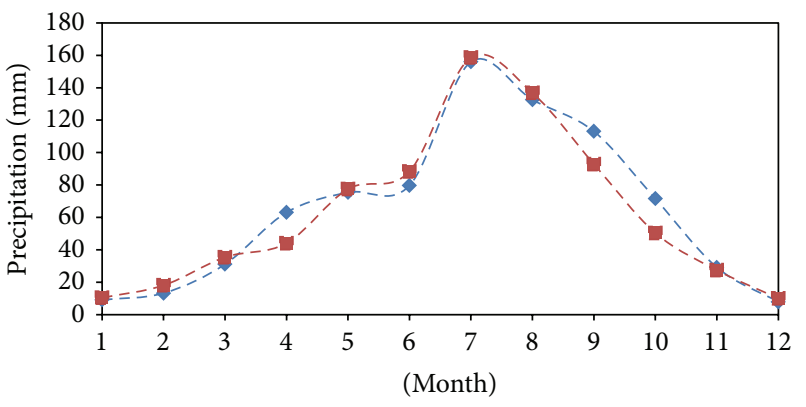

- - Prechange

-m - Postchange

FIGURE 14: Monthly precipitation for the prechange period and postchange period.

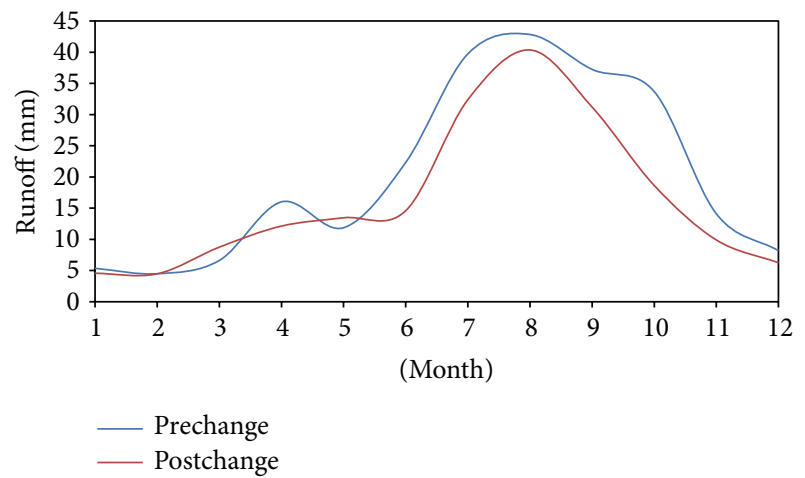

FIGURE 15: Monthly runoff for the prechange period and postchange period.

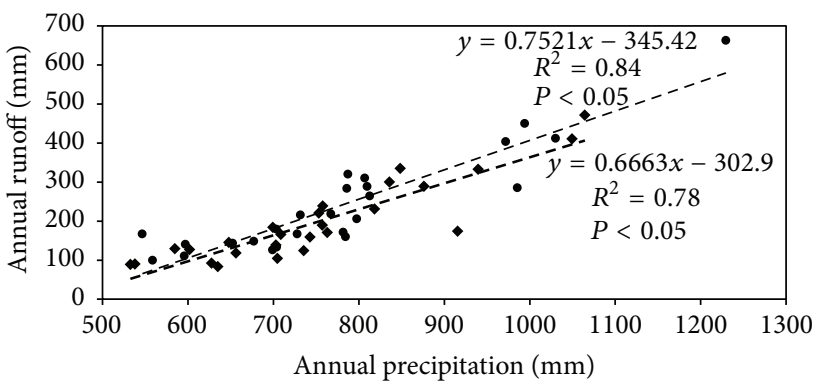

- Postchange period - - - Linear (postchange period)

- Prechange period - - - Linear (prechange period)

FIgURE 16: Correlation between precipitation and runoff for prechange period and postchange period.

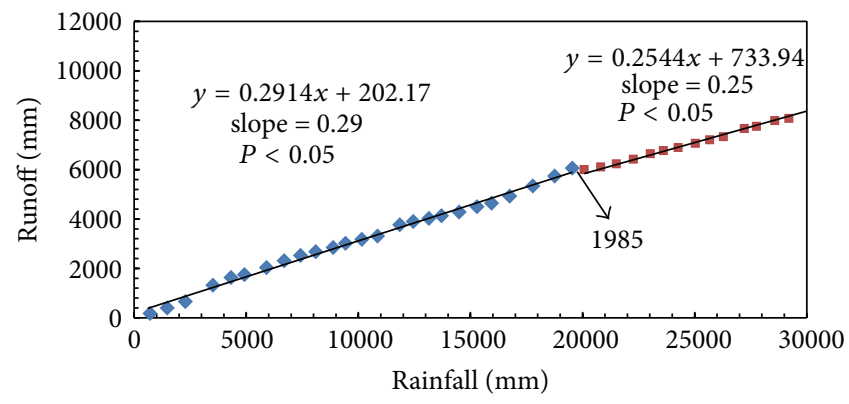

FIGURE 17: Double mass curve of annual precipitation and runoff. 

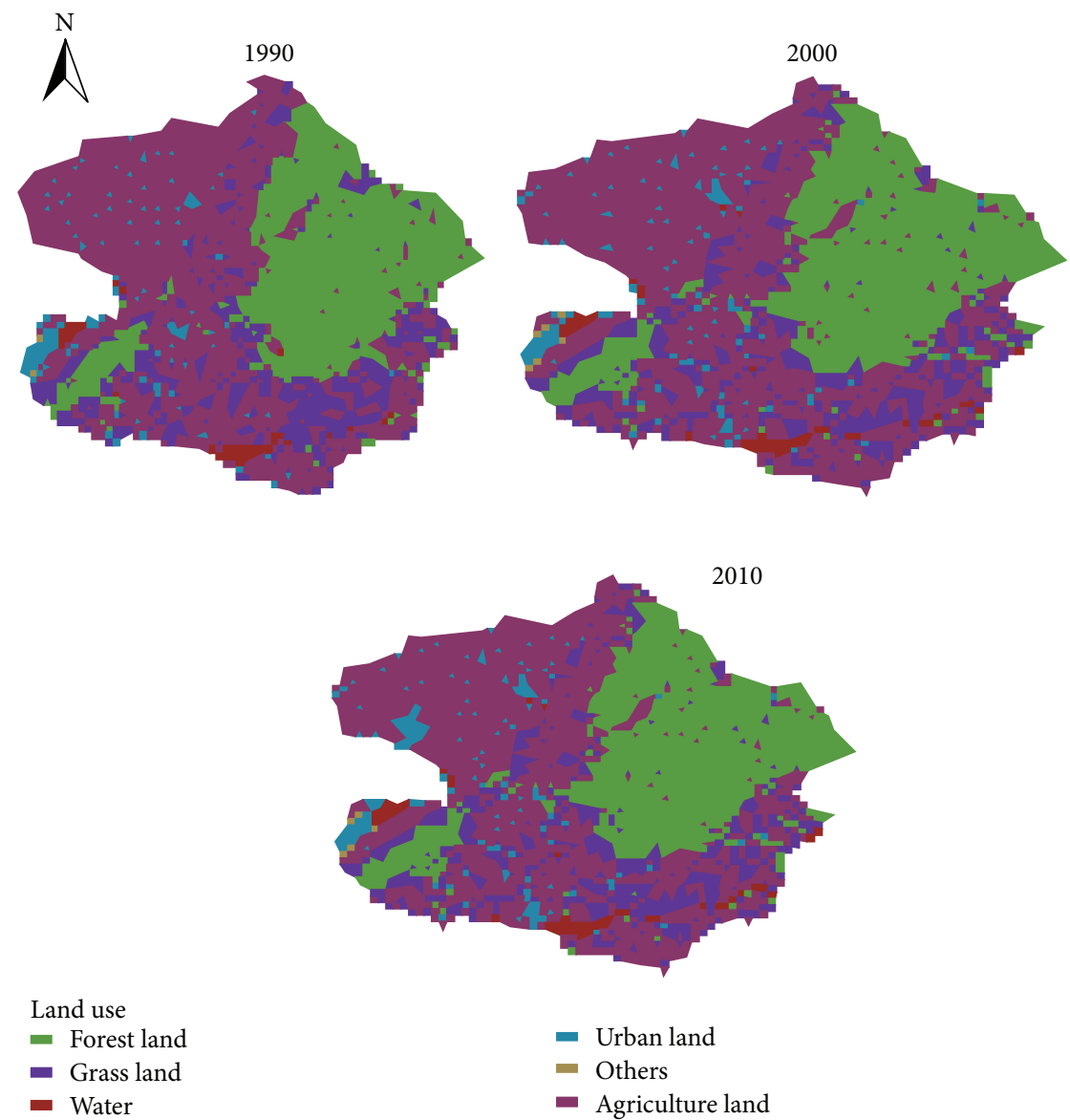

$$
\begin{aligned}
& \text { - Urban land } \\
& \text { - Others } \\
& \text { - Agriculture land }
\end{aligned}
$$

FIGURE 18: Land surface change of the study area from 1990, 2000, and 2010.

land increases from $4.26 \%$ to $5.26 \%$; meanwhile other uses of land type and water body also increased. During 20002010 , the area of urban land increased from $4.57 \%$ to $5.26 \%$, while it was only $4.2 \%$ during $1990-2000$. The agriculture land decreased from $45.95 \%$ to $45.82 \%$ in the first period. Meanwhile urban land increased by $4.26 \%$ to $5.26 \%$ in the whole study period (Figures 18 and 19). The land surface change in basin suggested that agriculture land has decreased in the 21st century, accompanied with the fast urbanization process and serious desertification.

For the Dongwan basin, the precipitation elasticity and simple linear regression method provided consistent results. Similar results were found for the Chaohe River [40]. Similar results were also found in some earlier studies in another area of China [20,21].

\section{Discussions}

In this study, two different approaches, that is, linear regression and precipitation elasticity methods, have been used to assess the impacts of the precipitation and land surface changes on runoff. In a comparison of the two approaches, the precipitation elasticity method is relatively simple and can be easily applied to other areas, and it gives a natural runoff

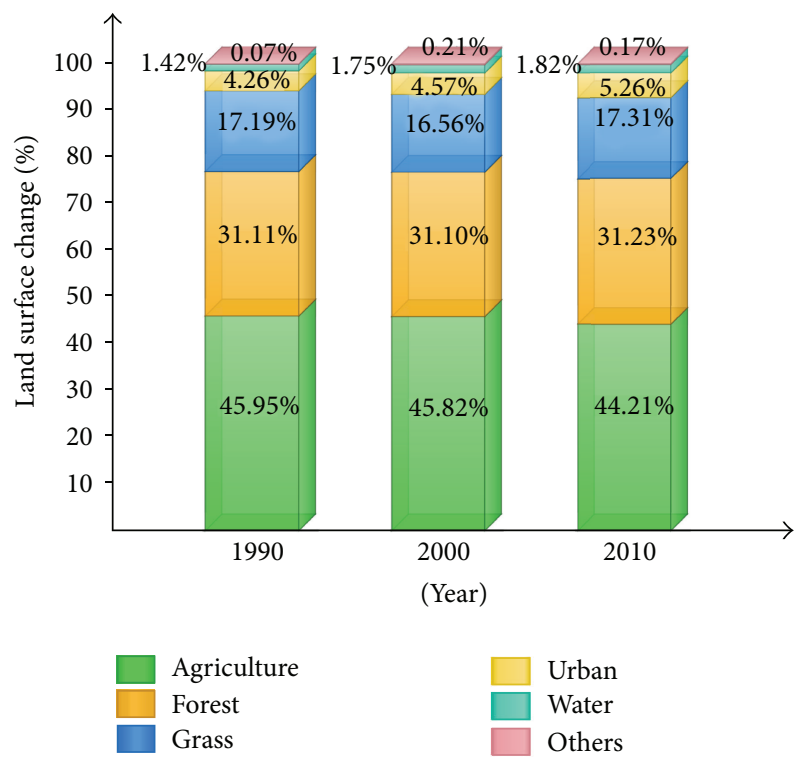

FIGURE 19: Variations in land cover of Yihe River basin during the study period.

change with lesser data and parameters. The simple linear regression method, on the other hand, is a statistical method. 
These two approaches were applied independently at the same time scale and showed highly consistent results. The main outcomes of this study agree with the finding of other studies [3, 6, 39, 41]. Yao et al. [23] found that there was an increase in land surface change after 1990 with a reduction in the runoff. Wang et al. [42] concluded that climate change was the main driving force for runoff decrease in midregion of the Yellow River. Over the decades, runoff due to human activities has continuously increased from $11 \%$ to $44 \%$. The land surface change increased due to the start of the project "Conservation of Cropland to Forest and Grassland Program (CCFGP)," which increased the area from $0.09\left(10^{4} \mathrm{hm}^{2}\right)$ to $3.41\left(10^{4} \mathrm{hm}^{2}\right)$ from 2000 to 2009 [43]. The construction of Dragon Island National Forest Park and other tourist activities has reduced the runoff of the basin [23].

Uncertainty arises from the assumption of the method that precipitation and land surface changes are independent of each other [22]. The precipitation variability and land surface changes are strongly related to each other and cannot be separable. The uncertainty may still exist, which overestimates or underestimates the runoff. Therefore, both methods have some uncertainty on the results to a certain extent. The further studies should be needed in the future to improve the quantitative estimation of precipitation variability and land surface impact on runoff with considering the uncertainties.

\section{Conclusions}

It is important to quantify the impacts of precipitation variability and land surface changes on runoff in the Yihe River basin. This study investigates the characteristics of changes in precipitation and runoff, during 1961-2011, in the Yihe River basin. Downward trends were found for precipitation and runoff using new method, that is, innovative trend pattern. Runoff series in the study area presented greater decline compared with the precipitation time series. An abrupt change in runoff can be found in 1985. The consistent results from precipitation elasticity and linear regression methods to quantify the impacts of precipitation variability and land surface changes in runoff were identified. Precipitation variability comprised up to 56.38 and $67.68 \%$ of the difference in annual runoff between the two periods by the two methods, that is, precipitation elasticity and linear regression, indicating that precipitation variability played main driving force in the runoff decrease. The role of land surface changes is increasing during the recent decades in runoff reduction due to the rapid growth of urbanization. The results obtained in this study would provide more evidence and useful reference for water resources planning and management in this region.

\section{Competing Interests}

The authors declare that they have no competing interests.

\section{Acknowledgments}

This work was supported by the National Natural Science Foundation of China (Grant nos. 41130639, 51179045, and 41201028) and the Non-Profit Industry Financial Program of Ministry of Water Resources of China (201501022 and 201301068) with combined funding from Higher Education Commission of Pakistan, the special program for scholars for Engineering Faculty Development.

\section{References}

[1] Y. He, F. Wang, X. Mu, H. Yan, and G. Zhao, "An assessment of human versus climatic impacts on Jing River Basin, Loess Plateau, China," Advances in Meteorology, vol. 2015, Article ID 478739, 13 pages, 2015.

[2] X. Zhou, Y.Zhang, and Y. Yang, "Comparison of two approaches for estimating precipitation elasticity of streamflow in China's Main River Basins," Advances in Meteorology, vol. 2015, Article ID 924572, 8 pages, 2015.

[3] Z. Bao, J. Zhang, G. Wang et al., "Attribution for decreasing streamflow of the Haihe River basin, northern China: climate variability or human activities?" Journal of Hydrology, vol. 460461, pp. 117-129, 2012.

[4] S. Zeng, C. Zhan, F. Sun, H. Du, and F. Wang, "Effects of climate change and human activities on surface runoff in the luan river basin," Advances in Meteorology, vol. 2015, Article ID 740239, 12 pages, 2015.

[5] G. Zhao, E. Li, X. Mu, Z. Wen, S. Rayburg, and P. Tian, "Changing trends and regime shift of streamflow in the Yellow River basin," Stochastic Environmental Research and Risk Assessment, vol. 29, no. 5, pp. 1331-1343, 2015.

[6] H. Chen, C.-Y. Xu, and S. Guo, "Comparison and evaluation of multiple GCMs, statistical downscaling and hydrological models in the study of climate change impacts on runoff," Journal of Hydrology, vol. 434-435, pp. 36-45, 2012.

[7] X. Yang, L. Ren, Y. Liu, D. Jiao, and S. Jiang, "Hydrological response to land use and land cover changes in a sub-watershed of West Liaohe River Basin, China," Journal of Arid Land, vol. 6, no. 6, pp. 678-689, 2014.

[8] S. Wang, Y. Yan, M. Yan, and X. Zhao, "Quantitative estimation of the impact of precipitation and human activities on runoff change of the Huangfuchuan River Basin," Journal of Geographical Sciences, vol. 22, no. 5, pp. 906-918, 2012.

[9] J. Fan, F. Tian, Y. Yang, S. Han, and G. Qiu, "Quantifying the magnitude of the impact of climate change and human activity on runoff decline in Mian River Basin, China," Water Science \& Technology, vol. 62, no. 4, pp. 783-791, 2010.

[10] Q. Li, X. Yu, Z. Xin, and Y. Sun, "Modeling the effects of climate change and human activities on the hydrological processes in a semiarid watershed of Loess Plateau," Journal of Hydrologic Engineering, vol. 18, no. 4, pp. 401-412, 2013.

[11] A. Zhang, C. Zhang, G. Fu, B. Wang, Z. Bao, and H. Zheng, "Assessments of impacts of climate change and human activities on runoff with SWAT for the Huifa River Basin, Northeast China," Water Resources Management, vol. 26, no. 8, pp. 21992217, 2012.

[12] S. Zeng, J. Xia, and H. Du, "Separating the effects of climate change and human activities on runoff over different time scales 
in the Zhang River basin," Stochastic Environmental Research and Risk Assessment, vol. 28, no. 2, pp. 401-413, 2014.

[13] F. Zhao, L. Zhang, Z. Xu, and D. F. Scott, "Evaluation of methods for estimating the effects of vegetation change and climate variability on streamflow," Water Resources Research, vol. 46, no. 3, Article ID W03505, 2010.

[14] N. Fohrer, S. Haverkamp, and H.-G. Frede, "Assessment of the effects of land use patterns on hydrologic landscape functions: development of sustainable land use concepts for low mountain range areas," Hydrological Processes, vol. 19, no. 3, pp. 659-672, 2005.

[15] N. Zégre, A. E. Skaugset, N. A. Som, J. J. McDonnell, and L. M. Ganio, "In lieu of the paired catchment approach: hydrologic model change detection at the catchment scale," Water Resources Research, vol. 46, no. 11, Article ID W11544, 2010.

[16] X. Li, Z. Li, and J. Dong, "Application of SWAT model in runoff simulation in upper reaches of Yihe River," Journal of Hohai University: Natural Sciences, vol. 37, no. 1, pp. 23-26, 2009 (Chinese).

[17] P. Huang, Z. Li, C. Yao, Q. Li, and M. Yan, "Spatial combination modeling framework of saturation-excess and infiltrationexcess runoff for semihumid watersheds," Advances in Meteorology, vol. 2016, Article ID 5173984, 15 pages, 2016.

[18] B. He, C. Miao, and W. Shi, "Trend, abrupt change, and periodicity of streamflow in the mainstream of Yellow River," Environmental Monitoring and Assessment, vol. 185, no. 7, pp. 6187-6199, 2013.

[19] P. Gao, X.-M. Mu, F. Wang, and R. Li, "Changes in streamflow and sediment discharge and the response to human activities in the middle reaches of the Yellow River," Hydrology and Earth System Sciences, vol. 15, no. 1, pp. 1-10, 2011.

[20] G. Zhao, P. Tian, X. Mu, J. Jiao, F. Wang, and P. Gao, "Quantifying the impact of climate variability and human activities on streamflow in the middle reaches of the Yellow River basin, China," Journal of Hydrology, vol. 519, pp. 387-398, 2014.

[21] S. Jiang, L. Ren, B. Yong, V. P. Singh, X. Yang, and F. Yuan, "Quantifying the effects of climate variability and human activities on runoff from the Laohahe basin in northern China using three different methods," Hydrological Processes, vol. 25, no. 16, pp. 2492-2505, 2011.

[22] H. Zheng, L. Zhang, R. Zhu, C. Liu, Y. Sato, and Y. Fukushima, "Responses of streamflow to climate and land surface change in the headwaters of the Yellow River Basin," Water Resources Research, vol. 45, no. 7, Article ID W00A19, 2009.

[23] C. Yao, L. Chang, J. Ding, Z. Li, D. An, and Y. Zhang, "Evaluation of the effects of underlying surface change on catchment hydrological response using the HEC-HMS model," in Proceedings of the International Association of Hydrological Sciences (ICWRS '14), vol. 364, pp. 145-150, Bologna, Italy, June 2014.

[24] J. Liu, W. Kuang, Z. Zhang et al., "Spatiotemporal characteristics, patterns, and causes of land-use changes in China since the late 1980s," Journal of Geographical Sciences, vol. 24, no. 2, pp. 195-210, 2014.

[25] H. B. Mann, "Nonparametric tests against trend," Econometrica, vol. 13, no. 3, pp. 245-259, 1945.

[26] M. G. Kendall, Rank Correlation Methods, Griffin, London, UK, 1975.
[27] R. Sneyers, Sur L’analyse Statistique des Séries D’observations, Secrétariat de l'Organisation Météorologique Mondiale, 1975.

[28] I. Ahmad, D. Tang, T. Wang, M. Wang, and B. Wagan, "Precipitation trends over time using mann-kendall and Spearman's rho tests in Swat River Basin, Pakistan," Advances in Meteorology, vol. 2015, Article ID 431860, 15 pages, 2015.

[29] M. Zaman, G. Fang, K. Mehmood, and M. Saifullah, “Trend change study of climate variables in Xin'anjiang-Fuchunjiang watershed, China," Advances in Meteorology, vol. 2015, Article ID 507936, 13 pages, 2015.

[30] Z. Şen, "Innovative trend analysis methodology," Journal of Hydrologic Engineering, vol. 17, no. 9, pp. 1042-1046, 2012.

[31] K. Saplioglu, M. Kilit, and B. K. Yavuz, "Trend analysis of streams in the Western Mediterranean Basin of Turkey," Fresenius Environmental Bulletin, vol. 23, no. 1, pp. 313-324, 2014.

[32] Z. Şen, “Trend identification simulation and application," Journal of Hydrologic Engineering, vol. 19, no. 3, pp. 635-642, 2014.

[33] A. N. Pettitt, "A nonparametric approach to the change-point problem," Journal of the Royal Statistical Society, Series C: Applied Statistics, vol. 28, no. 2, pp. 126-135, 1979.

[34] Y. Guo, Z. Li, M. Amo-Boateng, P. Deng, and P. Huang, "Quantitative assessment of the impact of climate variability and human activities on runoff changes for the upper reaches of Weihe River," Stochastic Environmental Research and Risk Assessment, vol. 28, no. 2, pp. 333-346, 2014.

[35] A. Sankarasubramanian, R. M. Vogel, and J. F. Limbrunner, "Climate elasticity of streamflow in the United States," Water Resources Research, vol. 37, no. 6, pp. 1771-1781, 2001.

[36] H. Alexandersson and A. Moberg, "Homogenization of Swedish temperature data. Part I: homogeneity test for linear trends," International Journal of Climatology, vol. 17, no. 1, pp. 25-34, 1997.

[37] H. Alexandersson, "A homogeneity test applied to precipitation data," Journal of Climatology, vol. 6, no. 6, pp. 661-675, 1986.

[38] T. A. Buishand, "Some methods for testing the homogeneity of rainfall records," Journal of Hydrology, vol. 58, no. 1-2, pp. 11-27, 1982.

[39] S. Peng, W. Liu, W. Wang et al., "Estimating the effects of climatic variability and human activities on streamflow in the Hutuo River Basin, China," Journal of Hydrologic Engineering, vol. 18, no. 4, pp. 422-430, 2013.

[40] W. Wang, Q. Shao, T. Yang et al., "Quantitative assessment of the impact of climate variability and human activities on runoff changes: a case study in four catchments of the Haihe River basin, China," Hydrological Processes, vol. 27, no. 8, pp. 1158-1174, 2013.

[41] H. Ma, D. Yang, S. K. Tan, B. Gao, and Q. Hu, "Impact of climate variability and human activity on streamflow decrease in the Miyun Reservoir catchment," Journal of Hydrology, vol. 389, no. 3-4, pp. 317-324, 2010.

[42] J. Wang, Y. Hong, J. Gourley, P. Adhikari, L. Li, and F. Su, "Quantitative assessment of climate change and human impacts on long-term hydrologic response: a case study in a sub-basin of the Yellow River, China," International Journal of Climatology, vol. 30, no. 14, pp. 2130-2137, 2010.

[43] Y. Qiu, Sustainable Land Use Change in the North West Provinces of China Research Reports, School of Economics and Government, Australian National University, 2007. 

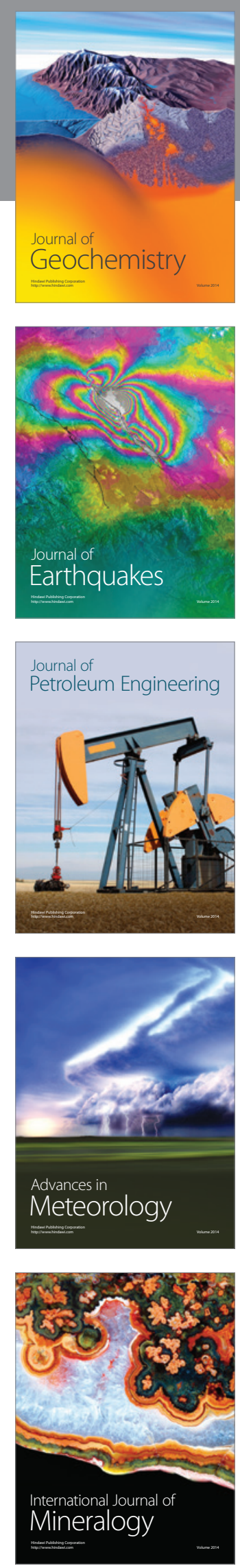
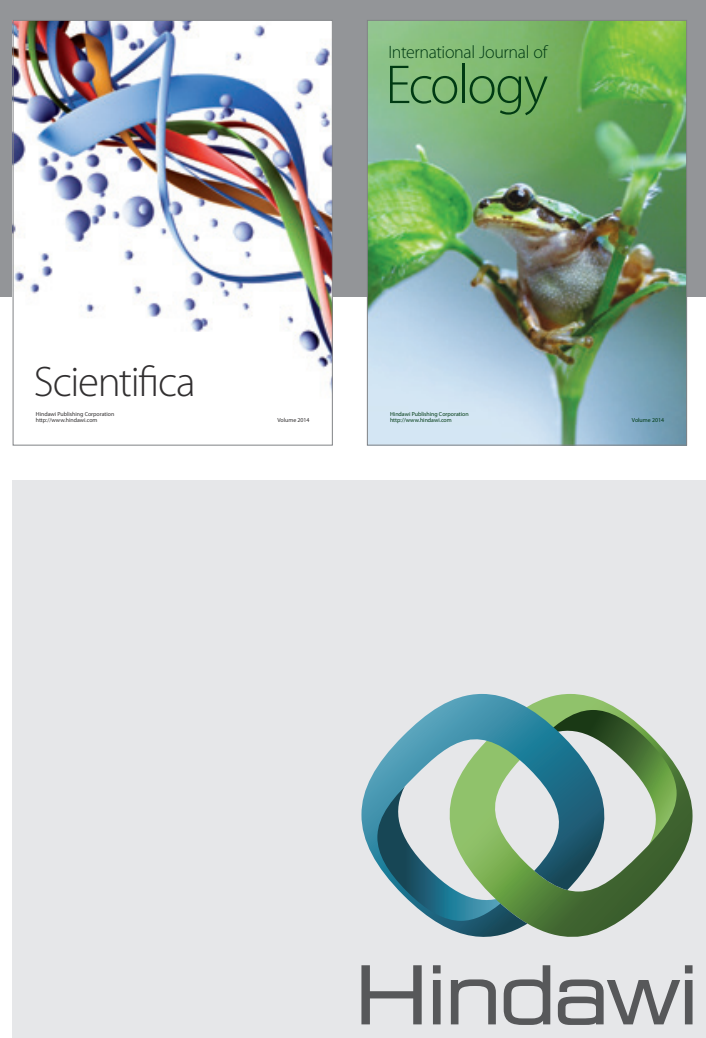

Submit your manuscripts at

http://www.hindawi.com
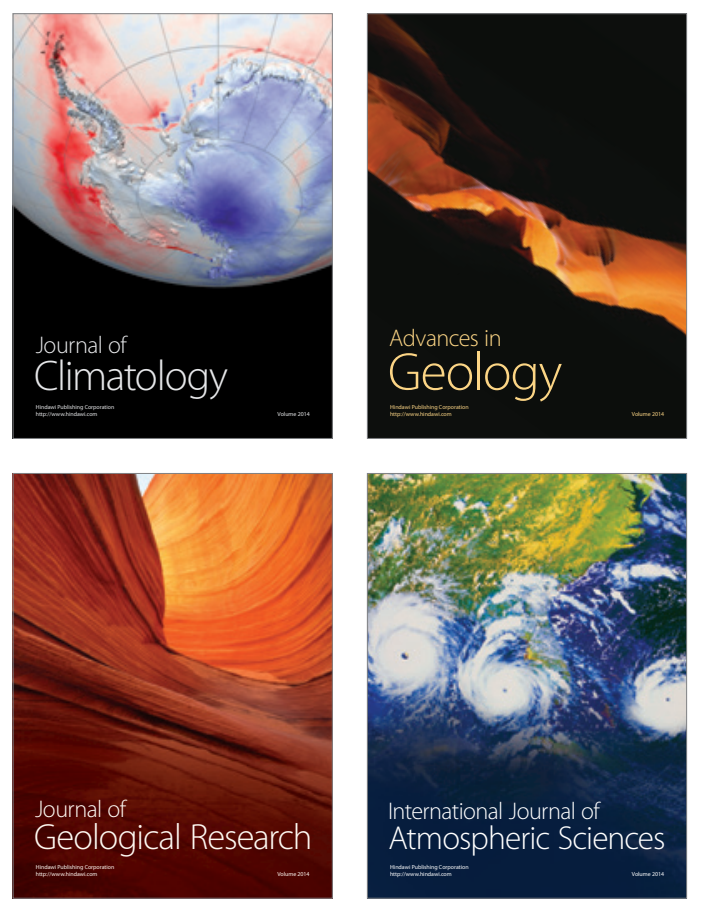

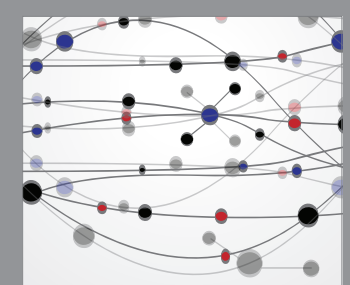

The Scientific

\section{World Journal}
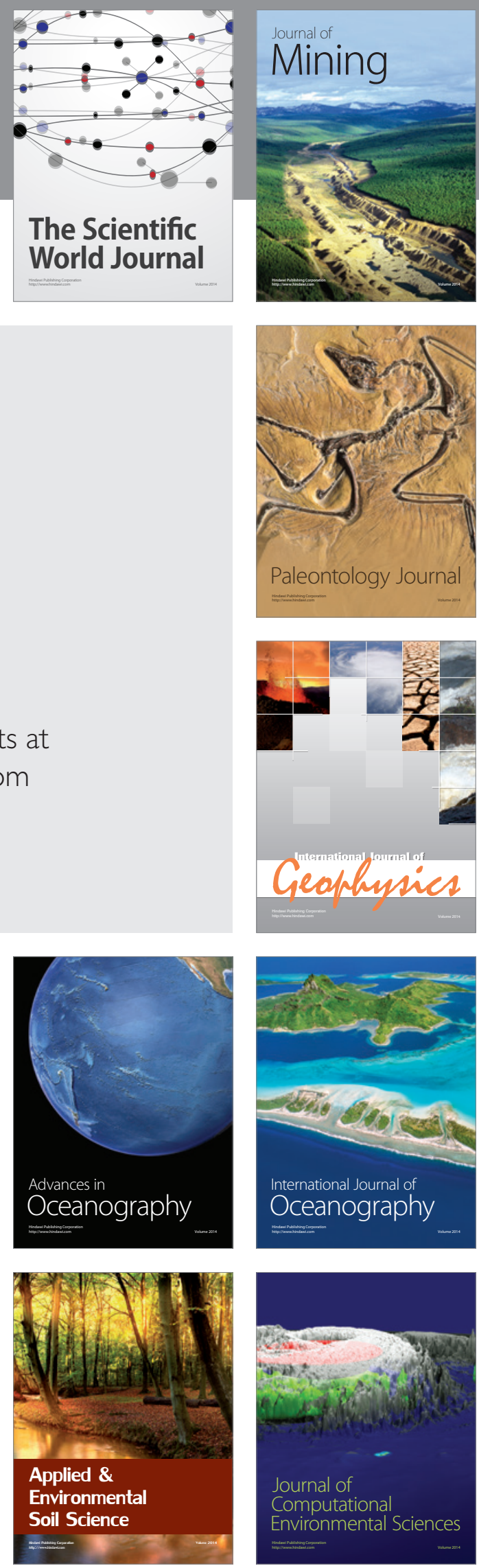